\title{
RESEARCH
}

\section{Lack of adrenal TSPO/PBR expression in hamsters reinforces correlation to triglyceride metabolism}

\author{
Prasanthi P Koganti and Vimal Selvaraj \\ Department of Animal Science, College of Agriculture and Life Sciences, Cornell University, Ithaca, New York, USA \\ Correspondence should be addressed to V Selvaraj: vs88@cornell.edu
}

\begin{abstract}
Despite being a highly conserved protein, the precise role of the mitochondrial translocator protein (TSPO), previously known as the peripheral benzodiazepine receptor (PBR), remains elusive. The void created by studies that overturned a presumptive model that described TSPO/PBR as a mitochondrial cholesterol transporter for steroidogenesis has been filled with evidence that it can affect mitochondrial metabolic functions across different model systems. We previously reported that TSPO/PBR deficient steroidogenic cells upregulate mitochondrial fatty acid oxidation and presented a strong positive correlation between TSPO/PBR expression and tissues active in triglyceride metabolism or lipid storage. Nevertheless, the highlighting of inconsistencies in prior work has provoked reprisals that threaten to stifle progress. One frequent factoid presented as being supportive of a cholesterol import function is that there are no steroidsynthesizing cell types without high TSPO/PBR expression. In this study, we examine the hamster adrenal gland that is devoid of lipid droplets in the cortex and largely relies on de novo cholesterol biosynthesis and uptake for steroidogenesis. We find that Tspo expression in the hamster adrenal is imperceptible compared to the mouse. This observation is consistent with a substantially low expression of Cpt1a in the hamster adrenal, indicating minimal mitochondrial fatty acid oxidation capacity compared to the mouse. These findings provide further reinforcement that the much soughtafter mechanism of TSPO/PBR function remains correlated with the extent of cellular triglyceride metabolism. Thus, TSPO/PBR could have a homeostatic function relevant only to steroidogenic systems that manage triglycerides associated with lipid droplets.
\end{abstract}
Key Words
- adrenal cortex
- steroidogenesis
- mitochondria
- cholesterol
- lipid droplets

\section{Introduction}

The precise function of the mitochondrial translocator protein (TSPO), previously known as the peripheral benzodiazepine receptor (PBR), has been an investigative question for decades (Gavish et al. 1999, Selvaraj \& Stocco 2015, Gavish \& Veenman 2018). Most proposed functions to date have been correlative or based on pharmacology, with a staple interest in drug discovery (Selvaraj \& Tu
2016). With no rigorous testing for off-target effects, these research outputs have created a kaleidoscopic collection of purported functions (Liu et al. 2014, Selvaraj et al. 2015, Gatliff \& Campanella 2016, Stocco et al. 2017). On this basis, TSPO-binding drugs have been proposed as therapeutic targets for a variety of conditions as represented by the patent landscape (Kim \& Pae 2016a,b). 
As a functional correlation to its abundant expression in the outer mitochondrial membrane of steroidogenic cells (Anholt et al. 1986), early pharmacological experiments in testicular Leydig cell lines reported TSPO function as linked to mitochondrial cholesterol import, the first step in de novo steroidogenesis (Mukhin et al. 1989, Krueger \& Papadopoulos 1990, Papadopoulos et al. 1990). These studies by Vassilios Papadopoulos came at a time when there was substantial interest in identifying the rate-limiting step to steroid hormone biosynthesis (Stocco $\&$ Clark 1996). Subsequent studies by the same group that disrupted the Tspo gene (Papadopoulos et al. 1997a) or knocked-down Tspo gene expression (Hauet et al. 2005), again in Leydig cell lines, reported dramatic reductions to steroidogenesis. These studies were performed in response to the identification of the STAR protein (Clark et al. 1994, Caron et al. 1997), which contested the involvement of TSPO in this process. In several subsequent manuscripts, interpretation was asserted in that TSPO was 'indispensable' for de novo steroidogenesis (Culty et al. 1999) and in vivo viability (Papadopoulos et al. 1997b). As such, pharmacological effects have been frequently explained by extrapolation to the broad functions of steroids (Rupprecht et al. 2010).

In stark contrast to these engendering reports that were all from the Papadopoulos group, recent studies disagreed. In vivo, both conditional and global TSPO knockout mice failed to demonstrate any overt problems including those associated with de novo steroidogenesis (Banati et al. 2014, Morohaku et al. 2014, Tu et al. 2014, Wang et al. 2016, Klee et al. 2019). One study suggested age-related subtle steroidogenic abnormalities that were secondary and independent of de novo steroidogenesis (Barron et al. 2018). In vitro, CRISPR/Cas9-mediated deletion of TSPO in Leydig cells, showed no association to steroid biosynthesis ( $\mathrm{Tu}$ et al. 2015) and, in glia, de novo steroidogenesis was confirmed independent of TSPO (Milenkovic et al. 2019). In support, the use of knockout models in studying TSPO-binding drugs have reported that effects are independent of TSPO (Tu et al. 2015, Singh et al. 2020). It has also been made clear that abundant TSPO expression is not exclusive to steroidsynthesizing cells; it is detectable in most tissue types with high expression also observed in brown and white adipose tissues ( $\mathrm{Tu}$ et al. 2016). These reveals have not only marked progress to understanding, but also aligned current work to seek the precise function of TSPO, expanding to test alternate assumptions (Šileikyte et al. 2014, Zhao et al. 2016). Regrettably, however, they also revealed the imprecise and irreproducible qualities of prior work on TSPO (reviewed in Selvaraj et al. 2015, Selvaraj \& Tu 2016). Studies have now correlated TSPO to affecting mitochondrial metabolism and autophagy (Gatliff et al. 2014, Tu et al. 2016, Milenkovic et al. 2019, Kim et al. 2020), a clear departure from any 'translocation' actions. Nevertheless, as none have pinpointed a mechanistic structure-function explanation for TSPO, it has been difficult for groups engaged in drug discovery to explain effects and putative links to TSPO.

Papadopoulos has also weighed in to maintain that TSPO is crucial for 'steroidogenesis' and continues to publish results that interpret such a function, albeit a direct link to mitochondrial cholesterol import in these studies are not supported (Selvaraj et al. 2016, Selvaraj \& Stocco 2018). We disagree with these misleading representations that force controversy, but do acknowledge that a TSPO function distinct from de novo steroid biosynthesis, common to all TSPO expressing cell types, could impact cellular physiology. The importance of TSPO function to long-term species survival is obviously indicated by its sequence conservation from bacteria to humans (Selvaraj \& Stocco 2015). However, it must be noted that conserved does not mean fundamental; fitness under specific constraints can also lead to conservation.

A frequent correlation presented in support of a function in steroidogenesis is that TSPO is abundant in steroid-producing mitochondria and that there are no steroid-synthesizing cell types without abundant TSPO expression (Chung et al. 2020). As we previously found a strong correlation between high TSPO expression and cell types active in triglyceride metabolism and/or contain abundant lipid droplets (Tu et al. 2016), we decided to examine tissue TSPO expression levels in the hamster that is almost completely devoid of lipid droplets in steroidogenic cells of the adrenal cortex (Alpert 1950, Lehoux \& Lefebvre 1980).

\section{Materials and methods}

\section{Animals}

Female C57BL/6 mice (8-10 weeks of age) and Syrian hamsters (Mesocricetus auratus; 10 weeks old) were killed for tissue collection. Adrenal glands, gonadal white adipose tissue, harderian glands and ovaries were dissected and processed. The tissues were either snap-frozen in liquid nitrogen for total RNA isolation or processed immediately. Animals were maintained in accordance to the $\mathrm{NIH}$ Guidelines for the Care and Use of Laboratory Animals. 
The Institutional Animal Care and Use Committee of Cornell University approved all experiments in this work.

\section{Histology}

Unfixed tissues from mice and hamsters were immediately embedded in optimal cutting temperature compound (Sakura Fine-Tek ${ }^{\circledR}$ ) and maintained frozen in $-80^{\circ} \mathrm{C}$. Frozen sections ( $5 \mu \mathrm{m}$ thickness) were cut using a cryostat (CM1950, Leica), collected on glass slides, and stained for neutral lipid deposits using Oil Red O (Matheson Coleman \& Bell). For staining, slides were first fixed with $4 \%$ formaldehyde during thaw for 60 min at room temperature and then washed with deionized water to remove the mounting compound. Sections were then immersed in Oil Red O dissolved in 60\% isopropyl alcohol and incubated for $30 \mathrm{~min}$ at room temperature. This was followed by washing with deionized water, counterstaining using Fast Green FCF (Millipore, Sigma) and mounting with a coverslip using glycerol. Slides were viewed using a light microscope (Leica DM750 LED) and images were acquired using a high definition color camera (Leica ICC50W).

\section{RNA isolation and CDNA synthesis}

Total RNA was isolated from adrenals, white adipose tissue, harderian glands and ovaries (three biological replicates each) from both mice and hamsters using TRIzol ${ }^{\mathrm{TM}}$ (Life Technologies). RT for cDNA synthesis was carried out for $2 \mu \mathrm{g}$ of total RNA using oligo-dT primers with the High Capacity cDNA RT kit (Applied Biosystems).

\section{Absolute gene expression}

Quantitation of Tspo expression was performed by generating a standard curve using a mouse Tspo template plasmid (pLenti-CMV-TSPO; Tu et al. 2016) using intronspanning primers that were common for both mouse and hamster Tspo sequences (Table 1). For this method, the plasmid was first linearized using Xba1 restriction digestion, followed by column purification (Zymo Research) and quantification (Nanophotometer N60, Implen). Mass of one copy of the linearized plasmid was determined by using the formula: mass $=($ size in $b p) \times(1.096 \mathrm{e}-21 \mathrm{~g} / \mathrm{bp})$. Total linearized plasmid DNA required for a specific Tspo copy number (highest concentration) was calculated by multiplying mass of plasmid by copy number desired (3e6 copies $/ \mu \mathrm{L}$ ). This concentration was diluted serially (tenfold) to achieve copy numbers extending the range from 3e6 to 3e-1 and DNA concentrations were confirmed. Standard quantitative PCR (qPCR) reactions were setup for each dilution in duplicate using Tspo primers, and amplification was quantified using SYBR-green, followed by melt curve analysis. Resulting cycle threshold (Ct) values were plotted against the known Tspo copy number for fitting a regression line, and a linear equation was obtained. Goodness-of-fit for the regression model was assessed using the coefficient of determination $\left(R^{2}\right)$. Copy numbers of Tspo in different tissue samples were determined from their respective $\mathrm{Ct}$ values from qPCR using this standard curve equation. Specificity and amplification efficiency of the common Tspo primers were confirmed. Statistical analysis for significant differences was performed for each tissue comparing values obtained for mice and hamsters using the Student's t-test (Prism,

Table 1 Primer sequences used for gene expression assays.

\begin{tabular}{ll}
\hline Gene & Hamster \\
\hline Tspo & 5'-CCCTTGGGTCTCTACACTGG-3' \\
Ldlr & 5'-ACCCCACTGACAAGCAGAAG-3' \\
Hsl & 5'-TCCTTGGCCATCTATGAGGAC-3' \\
Cpt1a & 5'-TGGGGACAAGAGGTTTTCAG-3' \\
& 5'-AAGCCCCAAAAGACCTCAGT-3' \\
Hmgcr & 5'-GCTGCCTCAGACACACTCCT-3' \\
& 5'-GTGCAGGGAACAGGAAGGA-3' \\
Cyp11a1 & 5'-CAAACGTGAGGGACTTGTCA-3' \\
Vdac1 & 5'-ATGCAGCAAACATCGTCACT-3' \\
& 5'-GCAGTTGGTCCCACTCCTAA-3' \\
Gapdha & 5'-TCGAAGTACCAGGTCATCCAC-3' \\
& 5'-TTGCAGTTGGCTACAAGACG-3' \\
& 5'-GCACATACCTGGCTTTAGGG-3' \\
& 5'-GCCTTCCGTGTTCCTACC-3' \\
& 5'-GCCTGCTTCACCACCTTC-3' \\
\hline
\end{tabular}

\begin{tabular}{l}
\hline mouse \\
\hline 5'-CCCTTGGGTCTCTACACTGG-3' \\
5'-ACCCCACTGACAAGCAGAAG-3' \\
5'-TCCCTGGGAACAACTTCACC-3' \\
5'-CACTCTTGTCGAAGCAGTCAG-3' \\
5'-TGGCACACCATTTTGACCTG-3' \\
5'-TTGCGGTTAGAAGCCACATAG-3' \\
5'-CTCAAACCTATTCGTCTTCTG-3' \\
5'-TTGGATGGTGTCTGTCTC-3' \\
5'-AGCTTGCCCGAATTGTATGTG-3' \\
5'-TCTGTTGTGAACCATGTGACTTC-3' \\
5'-AGGTCCTTCAATGAGATCCCTT-3' \\
5'-TCCCTGTAAATGGGGCCATAC-3' \\
5'-AAGTGAACAACTCCAGCCTGA-3' \\
5'-CACCAGCATTGACGTTCTTG-3' \\
5'-GCCTTCCGTGTTCCTACC-3' \\
5'-GCCTGCTTCACCACCTTC-3'
\end{tabular}

aPrimer sequences used were identical for both hamster and mouse.

https://joe.bioscientifica.com

https://doi.org/10.1530/JOE-20-0189 (c) 2020 Society for Endocrinology Published by Bioscientifica Ltd. Printed in Great Britain 
GraphPad). Differences were considered significant at $P<0.05$.

\section{Relative gene expression}

Expression differences for specific genes were analyzed using qPCR on cDNA prepared from different tissues. Assays were performed with SYBR-green quantitation using intron-spanning primers designed independently for mouse and hamster genes: low-density lipoprotein receptor $(L d l r)$, hormone-sensitive lipase (Hsl), carnitine palmitoyltransferase 1A (Cpt1a), 3-hydroxy3-methylglutaryl-CoA reductase ( $\mathrm{Hmgcr}$ ), cytochrome P450 family 11 subfamily A member 1 (Cyp11a1) and voltage-dependent anion-selective channel protein 1 (Vdac1). Results were analyzed after normalization to the expression of glyceraldehyde-3-phosphate (Gapdh) as an internal control. All primer sequences are provided in Table 1. Relative quantification of fold-change was performed comparing $\mathrm{Ct}$ values from individual mice by applying the $2^{-\Delta \Delta C t}$ method (Livak \& Schmittgen 2001). Statistical analysis for significant differences was performed comparing ovaries to adrenals within mice and hamsters using the Student's $t$-test (Prism, GraphPad). Differences were considered significant at $P<0.05$.

\section{Results}

\section{Hamster adrenal cortex is devoid of lipid droplets}

In order to investigate the relationship between Tspo expression levels and lipid metabolism, we chose to examine the hamster, which is distinct in its adrenal cholesterol sourcing for steroidogenesis. Staining for neutral lipids in frozen sections of the adrenals, harderian glands, and ovaries from mice and hamsters confirmed that the hamster adrenal cortex is devoid of intracellular lipid stores/droplets (Fig. 1). This was a systems divergence specific only to the adrenals as harderian glands and ovaries from both mice and hamsters showed morphologically comparable neutral lipid deposits within the expected functional compartments (Fig. 1). Secretory epithelial cells of the tubuloacini of the harderian glands contained lipid droplets in both species. The ovarian glandular interstitia and cells of the theca and granulosa layers showed lipid droplet content in both species.

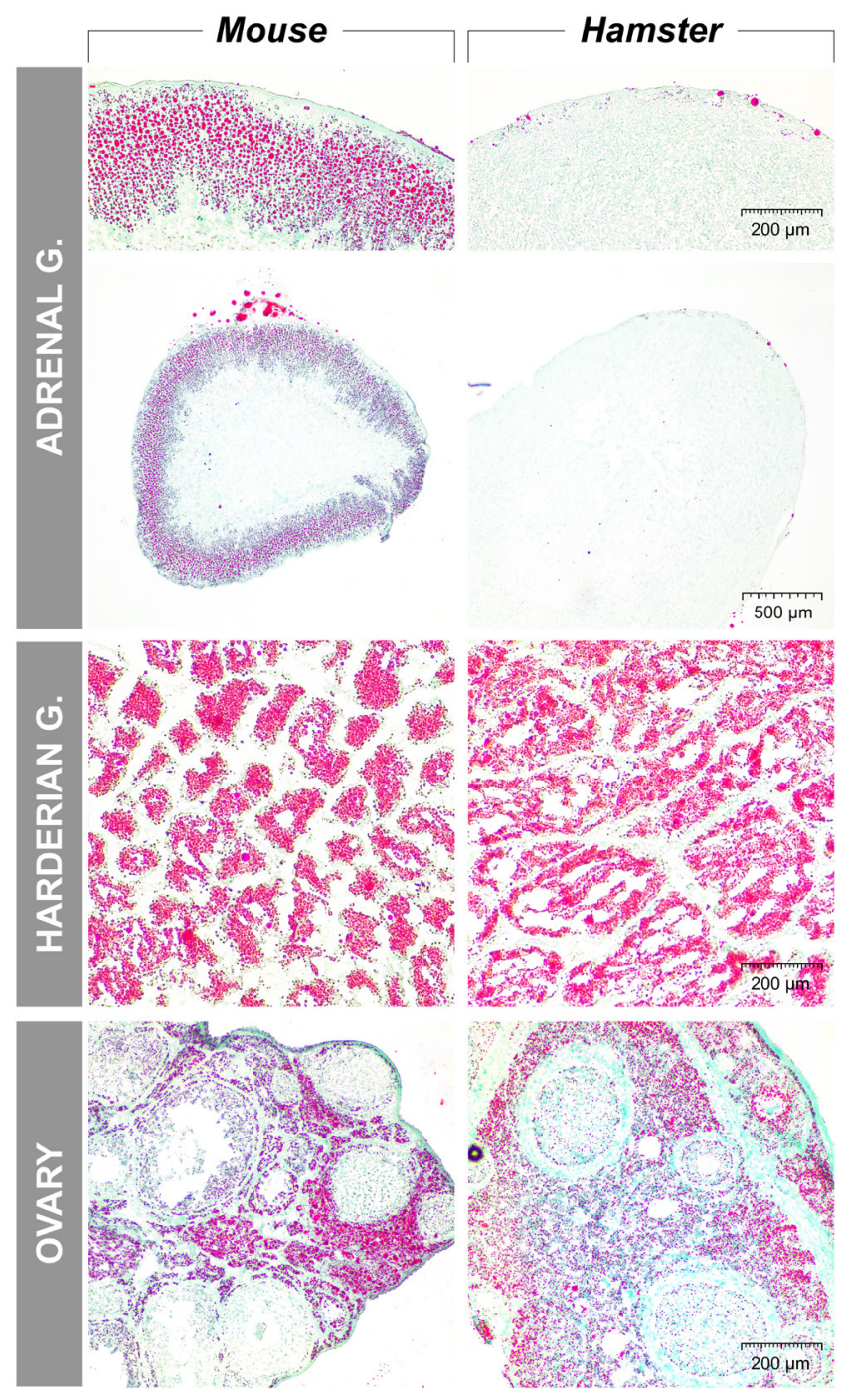

Figure 1

Hamster adrenocortical cells are devoid of lipid droplets. Comparing mouse and hamster tissues for neutral lipid staining shows that the hamster adrenal is devoid of large lipid stores as observed in the mouse. Harderian glands and ovaries show morphologically comparable organization of lipid stores between the two species.

\section{Imperceptible Tspo expression in adrenals of the hamster}

To directly compare Tspo gene expression between mouse and hamster tissues, we developed an absolute gene expression assay by generating a standard curve (regression line) with known Tspo copy numbers and using primers common for both species. We observed a strong coefficient of determination $\left(R^{2}=0.9956\right)$ between Tspo template copy number and the cycle threshold (Ct) detected in qPCR (Fig. 2A). This allowed not only a precise evaluation of Tspo gene expression levels, but also a 
A

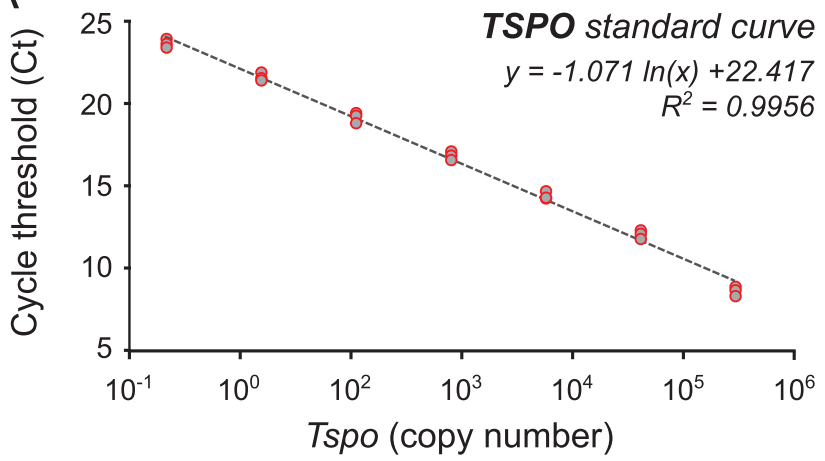

B

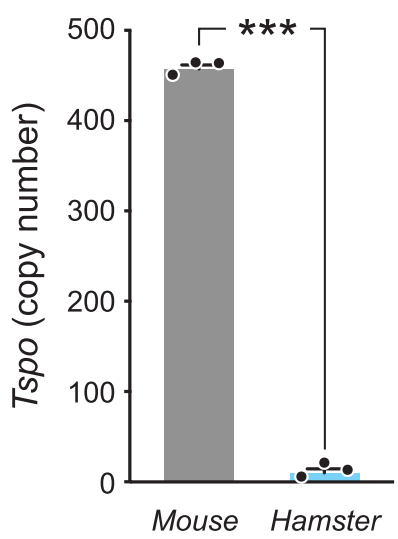

HARDERIAN G.

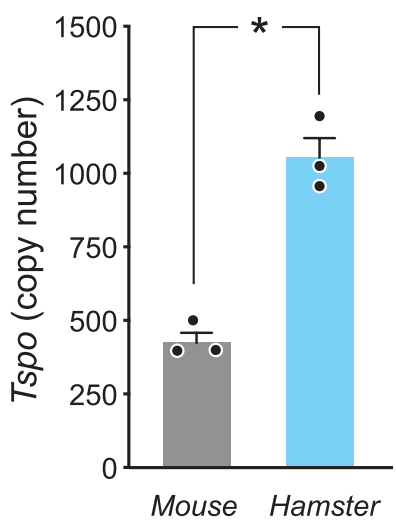

OVARY
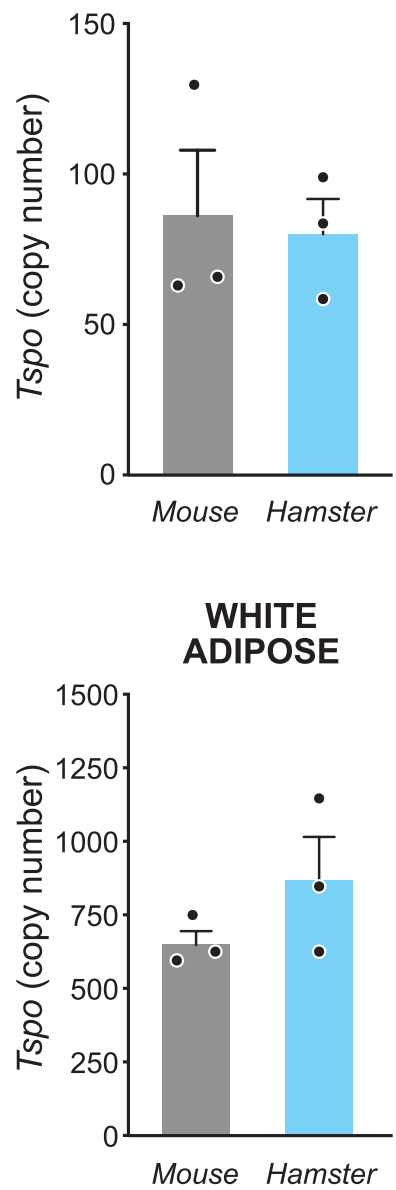

Figure 2

Hamster adrenal Tspo gene expression is imperceptible, a contrast to expression in mice. Regression line or standard curve generated with known Tspo copy numbers of a template plasmid using primers common for both the mouse and hamster genes (A). Absolute copy numbers of Tspo expression compared between adrenals, ovaries, harderian glands, and white adipose tissues of the mouse and hamster (B). Bars represent mean \pm S.E.M.; significant differences: $* P<0.01, * \star \star P<0.0001$.

comparison of the levels between the mouse and hamster. On this basis, our results showed that Tspo expression is imperceptible in hamster adrenals (mean copy number: 9.84) compared to mouse adrenals (mean copy number: 456.6); this was a 46-fold lower Tspo expression in hamster adrenals $(P<0.0001$; Fig. $2 \mathrm{~B})$. Such a difference in Tspo expression was not observed in comparing ovaries $(P=0.5906)$ between hamsters (mean copy number: 70.25) and mice (mean copy number: 85.40). Among other tissues known to express high levels of Tspo, expression in the hamster remained either equivalent or higher in hamsters compared to mice. Harderian gland Tspo expression was 2.5 -fold higher $(P<0.01)$ in hamsters (mean copy number: 1051.60) than mice (mean copy number: 423.48). White adipose tissue Tspo expression was not different $(P=0.3491)$ between hamsters (mean copy number: 865.47 ) and mice (mean copy number: 498.52).

\section{Distinct differences in cholesterol and triglyceride metabolism in hamster adrenals}

To compare steroidogenesis and lipid metabolic status between the mouse and hamster adrenals, we evaluated the expression of a few core genes involved in the regulation of these processes. We found that Cpt1a, a transferase essential for mitochondrial fatty acid oxidation (FAO), was substantially lower only in hamster adrenals relative to ovaries, but not in the mouse (Fig. 3A). Albeit not significant, expression of $L d l r$, involved in lipid uptake, was approximately four-fold higher in hamster adrenals relative to ovaries, but not in the mouse (Fig. 3B). Showing a similar trend but with statistical significance, Hmgcr, involved in cholesterol synthesis, was eight-fold higher in hamster adrenals relative to ovaries, but not in the mouse (Fig. 3C). Expression of $H s l$, an ester hydrolase involved in the release of free cholesterol and fatty acids from lipid droplet stores, was two-fold higher in mouse adrenals relative to ovaries, but not in the hamster (Fig. 3D). Expression of Star was 5.7-fold higher in the hamster adrenals relative to ovaries and 4.7-fold higher in mouse adrenals relative to ovaries (Fig. 3E). Albeit not significant, expression of Cyp11a1, the enzyme that converts cholesterol to the first steroid pregnenolone, was 0.6 -fold lower in the hamster adrenals relative to ovaries, but not in the mouse (Fig. 3F). Expression of Vdac1, an ion channel in the outer mitochondrial membrane, was not different in comparisons between adrenals and ovaries in both hamster and mice (Fig. 3G). 
A

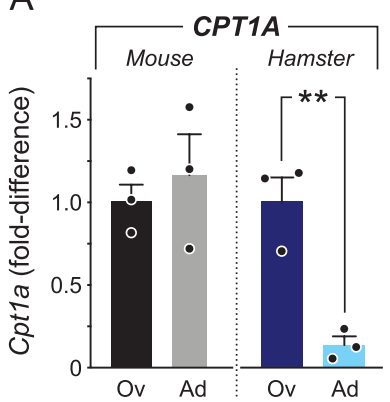

C

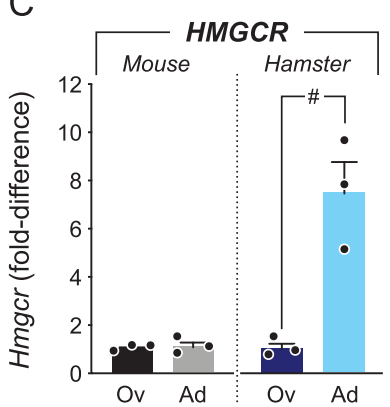

$E$

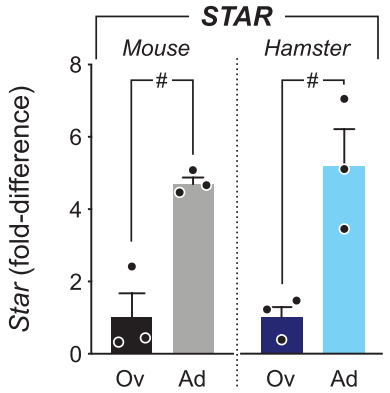

B

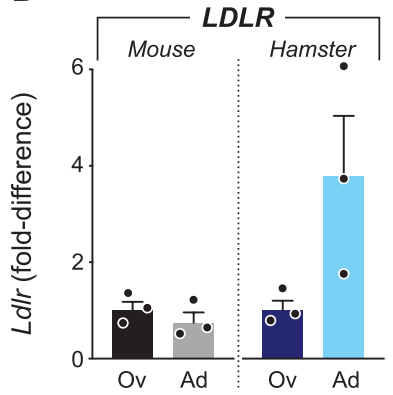

D

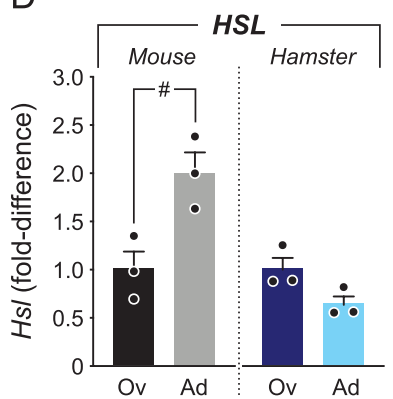

$\mathrm{F}$

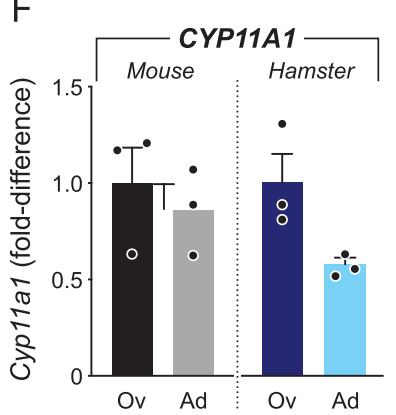

G

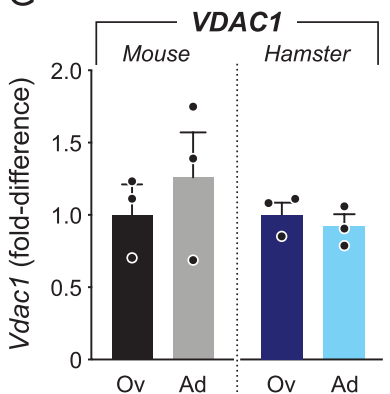

Figure 3

Expression of genes linked to cholesterol and triglyceride metabolism in the adrenals of hamsters and mice. Graphs show expression of (A) Cpt1a, (B) Ldlr, (C) Hmgcr, (D) Hsl, (E) Star, (F) Cyp11a1 and (G) Vdac1 in the adrenals (Ad) in comparison to levels detected in the ovary (Ov) of hamsters and mice. Disparate metabolic features are observed in that there are distinctly low levels of Cpt1a and high levels of Ldlr and HmgCr in the hamster adrenals compared to expression in the mouse adrenals. Bars represent mean \pm S.E.M.; significant differences: $\# P<0.05$; $\star \star P<0.001$

\section{Discussion}

Cholesterol esters stored in steroidogenic cell lipid droplets of the adrenal cortex can act as a reservoir for rapid release of free cholesterol (Zoller \& Malamed 1975, Bisgaier et al. 1985). Adrenocorticotropic hormone (ACTH) stimulation of adrenals results in ester hydrolysis and release of free cholesterol and triglyceride fatty acids (Vahouny et al. 1978). Esterase activity of Hsl, critical in this mobilization, acts on both cholesterol esters and triglycerides (Holm et al. 1988). As a result, cholesterol release from droplets is coupled to triglyceride release that needs to be concurrently processed by the cells (Freeman \& Ontko 1992). Although the specific disposition of these fatty acids remains to be delineated, pathophysiological accumulations have been shown to affect the rate of steroid biosynthesis (Sarel \& Widmaier 1995, Meikle et al. 1996). In contrast to mice, rats and humans, the hamster adrenal cortex is almost completely devoid of esterified cholesterol/lipid droplets (Alpert 1950, Lehoux \& Lefebvre 1980); a characteristic also confirmed in this study. This evolutionary divergence presents a unique physiology in that the hamster adrenal has substantial de novo cholesterol biosynthetic capability from endogenous substrates to meet the high demands for steroidogenesis (Lehoux \& Lefebvre 1980), at a rate almost 25 -fold higher than that recorded for the rat adrenal (Spady \& Dietschy 1985). Cholesterol accumulation from biosynthesis in hamster adrenals was also measured at a rate ten-fold greater than the kinetics of uptake via lowdensity lipoproteins (LDLs) (Spady \& Dietschy 1985). Our findings that indicate significantly higher hamster adrenal Hmgcr support these early reports. Higher levels of $L d l r$ expression also indicate an increased capacity to acquire lipids from extracellular sources in the hamster adrenal compared to the mouse adrenal. Correspondingly, with null lipid stores, the hamster adrenal cortex does not mobilize or process the considerable levels of triglycerides as observed in the adrenals of most other species. This is supported by hamster adrenal gene expression data that indicates dramatically lower mitochondrial FAO as shown by low Cpt1a. Levels of Star and Cyp11a1 were functionally comparable in the adrenals of the two species.

Before the link between TSPO/PBR and steroidogenesis was fostered (Mukhin et al. 1989, Krueger \& Papadopoulos 1990), a study that examined whole-body sections of neonatal rats with autoradiographic localization of TSPO using the small molecule [3H]Ro5-4864 concluded that expression of TSPO was correlated to tissues that derive their metabolic energy primarily from oxidative phosphorylation (Anholt et al. 1985). Supporting 
this early evidence, triglyceride metabolism research comparing inbred mouse strains identified Tspo/Pbr as one of the six candidate genes that could influence triglyceride metabolism in mice (Leduc et al. 2011). Experimentally, we provided the first evidence linking TSPO/PBR and fatty acid oxidation (FAO) by demonstrating that TSPO/ PBR deletion induces a shift in substrate utilization from glucose to fatty acids for energy production in steroidogenic cells and the adrenals ( $\mathrm{Tu}$ et al. 2016). Although the precise mechanism for this effect continues to be a topic of ongoing research, several other groups across different organisms/systems have recently reported similar findings regarding the shift to metabolism (Liu et al. 2017, Jurkiewicz et al. 2018, Kim et al. 2020). It must be noted that this shift is not homologous to evolution in the hamster because the inherent presence of lipid droplets in the adrenal cortex remained unchanged in Tspo gene deleted mice (Tu et al. 2014). It is not anticipated that a loss-/gain-of-function studies in model systems, particularly for quantitative traits as noted for TSPO (Leduc et al. 2011), would represent the gamut of adaptations during evolution that conserves systemic function.

Divergence from dependence on lipid droplet stores could be considered the hallmark of adrenal steroidogenesis evolution in the hamster. In this context, conservation of TSPO expression was apparently not critical, supporting the correlation between TSPO and triglyceride metabolism rather than mitochondrial cholesterol import. Considering in entirety from trophic signaling to steroid hormone release, systemic coevolution, not only pertaining to energy metabolism, but also mechanisms that determine sourcing and traffic of cholesterol to the mitochondria, upstream of import, remain to be dissected in the hamster adrenal. For mitochondrial cholesterol import, it is clear that the critical role of STAR (Caron et al. 1997) is not dependent on TSPO (Morohaku et al. 2014, Tu et al. 2015). Although the mechanism of STAR-mediated mitochondrial cholesterol import remains to be fully elucidated (Miller \& Bose 2011), it has been demonstrated that STAR is active prior to entry into the mitochondria (Arakane et al. 1996, 1998). Updated investigations on STAR and associated mitochondrial entry apparatus (Rajapaksha et al. 2013, Prasad et al. 2015) do not indicate TSPO involvement as previously suggested (Hauet et al. 2005).

Expression of Vdac1, a purported binding partner (McEnery et al. 1992), that resulted in the inclusion of TSPO in the mitochondrial permeability transition pore, was not different between the hamster and mouse adrenals.
It must be noted that TSPO involvement in mitochondrial permeability transition was disproven by studies using Tspo knockout mice (Šileikyte et al. 2014). Notwithstanding, levels of Vdac1 indicated that mitochondrial content was comparable in the adrenals of the two species.

High TSPO expression in harderian glands has been documented in early studies (Verma et al. 1987). Associated with the orbit and releasing secretions on the surface of the nictitating membrane, these glands are absent in higher primates (Payne 1994). Lipids are their major secretory product in rodents (including mouse and hamster), releasing 1-alkyl-2,3-diacylglycerol that might act as a lubricant (Lin \& Nadakavukaren 1981, Tvrzická et al. 1988). The murine harderian gland is known to have two epithelial cell types with different secretory products (Woodhouse \& Rhodin 1963). Interestingly, female Syrian hamsters possess a harderian gland with only one epithelial cell type with clear distinctions to lipid droplet sizes (Bucana \& Nadakavukaren 1973). Such intracellular specializations make the gland in each species functionally relevant. Our findings that indicate higher levels of Tspo in the hamster harderian glands compared to the mouse could be a result of these finer functional distinctions in these two species that might demand different respective levels of lipid metabolism.

Despite the unknowns regarding the concurrent evolution of lipid droplet loss and Tspo expression in the hamster adrenal glands, our findings advance understanding with two core interpretations: (1) there exist steroidogenic systems in nature without TSPO, supporting that it is not directly involved in the cholesterol to steroid biosynthesis process and (2) TSPO expression is consistently correlated to the level of triglyceride metabolism, a realistic step toward uncovering its physiological function.

It was not possible to examine hamster TSPO protein expression as there were no available species-specific antibodies. We attempted this using the following antibodies: (1) MAB from rabbit (C-terminal epitope from human, aa156-169, \#ab109497, Abcam) (Morohaku et al. 2013); (2) polyclonal antibody raised in rabbit (N-terminal epitope from rat, sequence proprietary, \#ab154878, Abcam); (3) polyclonal antibody raised in rabbits (N-terminal epitope from human, aa1-50; \#A15649, ABclonal), and we did not detect cross-reactivity with hamster TSPO. Nonetheless, we do not believe that this impacts our interpretations in any way, as regulation of TSPO is at the transcriptional level and there exists strong transcript-protein correlation in all tissues examined (Wang et al. 2012).

In summary, Tspo research has been plagued with an overwhelming array of effects and functional justifications 
that fail to provide any directional clarity toward a physiological function. We disagree with reports that attempt to repudiate work that refuted TSPO involvement in mitochondrial cholesterol import for steroidogenesis. It is extremely important that pharmacologists use Tspo gene disrupted mice or cells for target validation in reporting TSPO-associated functions. It is becoming increasingly clear that TSPO function, albeit not acutely essential, acts to provide some core aspects of organismal fitness that becomes vital for long-term survival of species.

\section{Declaration of interest}

The authors declare that there is no conflict of interest that could be perceived as prejudicing the impartiality of the research reported.

\section{Funding}

Funding for this study was from the National Institutes of Health (Grant Number DK110059) to V S.

\section{Acknowledgement}

The authors sincerely thank Dr Yung-Fu Chang at the College of Veterinary Medicine, Cornell University, for providing samples from Syrian hamsters.

\section{References}

Alpert M 1950 Observations on the histophysiology of the adrenal gland of the golden hamster. Endocrinology 46 166-176. (https://doi. org/10.1210/endo-46-2-166)

Anholt RR, De Souza EB, Oster-Granite ML \& Snyder SH 1985 Peripheraltype benzodiazepine receptors: autoradiographic localization in whole-body sections of neonatal rats. Journal of Pharmacology and Experimental Therapeutics 233 517-526.

Anholt RRH, Pedersen PL, De Souza EB \& Snyder SH 1986 The peripheraltype benzodiazepine receptor, localization to the mitochondrial outer membrane. Journal of Biological Chemistry 261 576-583.

Arakane F, Sugawara T, Nishino H, Liu Z, Holt JA, Pain D, Stocco DM, Miller WL \& Strauss 3rd JF 1996 Steroidogenic acute regulatory protein (StAR) retains activity in the absence of its mitochondrial import sequence: implications for the mechanism of StAR action. PNAS 93 13731-13736. (https://doi.org/10.1073/pnas.93.24.13731)

Arakane F, Kallen CB, Watari H, Foster JA, Sepuri NBV, Pain D, Stayrook SE, Lewis M, Gerton GL \& Strauss JF 1998 The mechanism of action of steroidogenic acute regulatory protein (StAR): StAR acts on the outside of mitochondria to stimulate steroidogenesis. Journal of Biological Chemistry 273 16339-16345. (https://doi.org/10.1074/ jbc.273.26.16339)

Banati RB, Middleton RJ, Chan R, Hatty CR, Kam WW, Quin C, Graeber MB, Parmar A, Zahra D, Callaghan P, et al. 2014 Positron emission tomography and functional characterization of a complete PBR/TSPO knockout. Nature Communications 5 5452. (https://doi. org/10.1038/ncomms6452)

Barron AM, Ji B, Kito S, Suhara T \& Higuchi M 2018 Steroidogenic abnormalities in translocator protein knockout mice and significance in the aging male. Biochemical Journal 475 75-85. (https://doi. org/10.1042/BCJ20170645)

Bisgaier CL, Chanderbhan R, Hinds RW \& Vahouny GV 1985 Adrenal cholesterol esters as substrate source for steroidogenesis. Journal of Steroid Biochemistry 23 967-974. (https://doi.org/10.1016/00224731(85)90054-8)

Bucana CD \& Nadakavukaren MJ 1973 Ultrastructural investigation of the postnatal development of the hamster harderian gland - II. Male and female. Zeitschrift Für Zellforschung Und Mikroskopische Anatomie 142 1-12. (https://doi.org/10.1007/BF00306700)

Caron KM, Soo SC, Wetsel WC, Stocco DM, Clark BJ \& Parker KL 1997 Targeted disruption of the mouse gene encoding steroidogenic acute regulatory protein provides insights into congenital lipoid adrenal hyperplasia. PNAS 94 11540-11545. (https://doi.org/10.1073/ pnas.94.21.11540)

Chung JY, Chen H, Papadopoulos V \& Zirkin B 2020 Cholesterol accumulation, lipid droplet formation, and steroid production in Leydig cells: role of translocator protein (18-kDa). Andrology 8 719-730. (https://doi.org/10.1111/andr.12733)

Clark BJ, Wells J, King SR \& Stocco DM 1994 The purification, cloning, and expression of a novel luteinizing hormone-induced mitochondrial protein in MA-10 mouse Leydig tumor cells. Characterization of the steroidogenic acute regulatory protein (StAR). Journal of Biological Chemistry $26928314-28322$.

Culty M, Li H, Boujrad N, Amri H, Vidic B, Bernassau JM, Reversat JL \& Papadopoulos V 1999 In vitro studies on the role of the peripheraltype benzodiazepine receptor in steroidogenesis. Journal of Steroid Biochemistry and Molecular Biology 69 123-130. (https://doi. org/10.1016/s0960-0760(99)00056-4)

Freeman DA \& Ontko JA 1992 Accumulation and mobilization of triglycerides and cholesteryl esters in Leydig tumor cells. Journal of Lipid Research 33 1139-1146.

Gatliff J \& Campanella M 2016 TSPO: kaleidoscopic 18-kDa amid biochemical pharmacology, control and targeting of mitochondria. Biochemical Journal 473 107-121. (https://doi.org/10.1042/ BJ20150899)

Gatliff J, East D, Crosby J, Abeti R, Harvey R, Craigen W, Parker P \& Campanella M 2014 TSPO interacts with VDAC1 and triggers a ROS-mediated inhibition of mitochondrial quality control. Autophagy 10 2279-2296. (https://doi.org/10.4161/15548627.2014.9 91665)

Gavish M \& Veenman L 2018 Regulation of mitochondrial, cellular, and organismal functions by TSPO. Advances in Pharmacology 82 103-136 (https://doi.org/10.1016/bs.apha.2017.09.004)

Gavish M, Bachman I, Shoukrun R, Katz Y, Veenman L, Weisinger G \& Weizman A 1999 Enigma of the peripheral benzodiazepine receptor. Pharmacological Reviews 51 629-650.

Hauet T, Yao ZX, Bose HS, Wall CT, Han Z, Li W, Hales DB, Miller WL, Culty M \& Papadopoulos V 2005 Peripheral-type benzodiazepine receptor-mediated action of steroidogenic acute regulatory protein on cholesterol entry into leydig cell mitochondria. Molecular Endocrinology 19 540-554. (https://doi.org/10.1210/me.2004-0307)

Holm C, Kirchgessner TG, Svenson KL, Fredrikson G, Nilsson S, Miller CG, Shively JE, Heinzmann C, Sparkes RS \& Mohandas T 1988 Hormone-sensitive lipase: sequence, expression, and chromosomal localization to 19 cent-q13.3. Science 241 1503-1506. (https://doi. org/10.1126/science.3420405)

Jurkiewicz P, Melser S, Maucourt M, Ayeb H, Veljanovski V, ManetaPeyret L, Hooks M, Rolin D, Moreau P \& Batoko H 2018 The multistress-induced translocator protein (TSPO) differentially modulates storage lipids metabolism in seeds and seedlings. Plant Journal 96 274-286. (https://doi.org/10.1111/tpj.14028)

Kim T \& Pae AN $2016 a$ Translocator protein (TSPO) ligands for the diagnosis or treatment of neurodegenerative diseases: a patent review (2010-2015; part 2) Expert Opinion on Therapeutic Patents 26 1353-1366. (https://doi.org/10.1080/13543776.2016.1230605) https://joe.bioscientifica.com https://doi.org/10.1530/JOE-20-0189 (c) 2020 Society for Endocrinology Published by Bioscientifica Ltd. Printed in Great Britain 
Kim T \& Pae AN 2016b Translocator protein (TSPO) ligands for the diagnosis or treatment of neurodegenerative diseases: a patent review (2010-2015; part 1) Expert Opinion on Therapeutic Patents 26 1325-1351. (https://doi.org/10.1080/13543776.2016.1230606)

Kim S, Kim N, Park S, Jeon Y, Lee J, Yoo SJ, Lee JW, Moon C, Yu SW \& Kim EK 2020 Tanycytic TSPO inhibition induces lipophagy to regulate lipid metabolism and improve energy balance. Autophagy 16 1200-1220. (https://doi.org/10.1080/15548627.2019.1659616)

Klee K, Storti F, Barben M, Samardzija M, Langmann T, Dunaief J \& Grimm C 2019 Systemic knockout of Tspo in mice does not affect retinal morphology, function and susceptibility to degeneration. Experimental Eye Research 188 107816. (https://doi.org/10.1016/j. exer.2019.107816)

Krueger KE \& Papadopoulos V 1990 Peripheral-type benzodiazepine receptors mediate translocation of cholesterol from outer to inner mitochondrial membranes in adrenocortical cells. Journal of Biological Chemistry 265 15015-15022.

Leduc MS, Hageman RS, Verdugo RA, Tsaih SW, Walsh K, Churchill GA \& Paigen B 2011 Integration of QTL and bioinformatic tools to identify candidate genes for triglycerides in mice. Journal of Lipid Research 52 1672-1682. (https://doi.org/10.1194/jlr.M011130)

Lehoux JG \& Lefebvre A 1980 De novo synthesis of corticosteroids in hamster adrenal glands. Journal of Steroid Biochemistry 12 479-485. (https://doi.org/10.1016/0022-4731(80)90310-6)

Lin WL \& Nadakavukaren MJ 1981 Harderian gland lipids of male and female golden hamsters. Comparative Biochemistry and Physiology Part B 70 627-630. (https://doi.org/10.1016/0305-0491(81)90308-4)

Liu GJ, Middleton RJ, Hatty CR, Kam WWY, Chan R, Pham T, Harrison-Brown M, Dodson E, Veale K \& Banati RB 2014 The 18 $\mathrm{kDa}$ translocator protein, microglia and neuroinflammation. Brain Pathology 24 631-653. (https://doi.org/10.1111/bpa.12196)

Liu GJ, Middleton RJ, Kam WWY, Chin DY, Hatty CR, Chan RHY \& Banati RB 2017 Functional gains in energy and cell metabolism after TSPO gene insertion. Cell Cycle 16 436-447. (https://doi.org/10.1080/ 15384101.2017.1281477)

Livak KJ \& Schmittgen TD 2001 Analysis of relative gene expression data using real-time quantitative PCR and the 2- $\Delta \Delta$ CT method. Methods 25 402-408. (https://doi.org/10.1006/meth.2001.1262)

McEnery MW, Snowman AM, Trifiletti RR \& Snyder SH 1992 Isolation of the mitochondrial benzodiazepine receptor: association with the voltage-dependent anion channel and the adenine nucleotide carrier. PNAS 89 3170-3174. (https://doi.org/10.1073/pnas.89.8.3170)

Meikle AW, Cardoso De Sousa JC, Hanzalova J \& Murray DK 1996 Oleic acid inhibits cholesteryl esterase and cholesterol utilization for testosterone synthesis in mouse Leydig cells. Metabolism: Clinical and Experimental 45 293-299. (https://doi.org/10.1016/S00260495(96)90281-4)

Milenkovic VM, Slim D, Bader S, Koch V, Heinl ES, Alvarez-Carbonell D, Nothdurfter C, Rupprecht R \& Wetzel CH 2019 CRISPR-cas9 mediated TSPO gene knockout alters respiration and cellular metabolism in human primary microglia cells. International Journal of Molecular Sciences 20 3359. (https://doi.org/10.3390/ijms20133359)

Miller WL \& Bose HS 2011 Early steps in steroidogenesis: intracellular cholesterol trafficking. Journal of Lipid Research 52 2111-2135. (https://doi.org/10.1194/jlr.R016675)

Morohaku K, Phuong NS \& Selvaraj V 2013 Developmental expression of translocator protein/peripheral benzodiazepine receptor in reproductive tissues. PLOS ONE $\mathbf{8}$ e74509. (https://doi.org/10.1371/ journal.pone.0074509)

Morohaku K, Pelton SH, Daugherty DJ, Butler WR, Deng W \& Selvaraj V 2014 Translocator protein/peripheral benzodiazepine receptor is not required for steroid hormone biosynthesis. Endocrinology 155 89-97. (https://doi.org/10.1210/en.2013-1556)

Mukhin AG, Papadopoulos V, Costa E \& Krueger KE 1989 Mitochondrial benzodiazepine receptors regulate steroid biosynthesis. PNAS $\mathbf{8 6}$ 9813-9816. (https://doi.org/10.1073/pnas.86.24.9813)
Papadopoulos V, Mukhin AG, Costa E \& Krueger KE 1990 The peripheraltype benzodiazepine receptor is functionally linked to Leydig cell steroidogenesis. Journal of Biological Chemistry 265 3772-3779.

Papadopoulos V, Amri H, Li H, Boujrad N, Vidic B \& Garnier M 1997 a Targeted disruption of the peripheral-type benzodiazepine receptor gene inhibits steroidogenesis in the R2C Leydig tumor cell line. Journal of Biological Chemistry 272 32129-32135. (https://doi. org/10.1074/jbc.272.51.32129)

Papadopoulos V, Amri H, Boujrad N, Cascio C, Culty M, Garnier M, Hardwick M, Li H, Vidic B, Brown AS, et al. 1997 b Peripheral benzodiazepine receptor in cholesterol transport and steroidogenesis. Steroids 62 21-28. (https://doi.org/10.1016/S0039-128X(96)00154-7)

Payne AP 1994 The harderian gland: a tercentennial review. Journal of Anatomy 185 1-49.

Prasad M, Kaur J, Pawlak KJ, Bose M, Whittal RM \& Bose HS 2015 Mitochondria-associated endoplasmic reticulum membrane (MAM) regulates steroidogenic activity via steroidogenic acute regulatory protein (StAR)-voltage-dependent anion channel 2 (VDAC2) interaction. Journal of Biological Chemistry 290 2604-2616. (https:// doi.org/10.1074/jbc.M114.605808)

Rajapaksha M, Kaur J, Bose M, Whittal RM \& Bose HS 2013 Cholesterolmediated conformational changes in the steroidogenic acute regulatory protein are essential for steroidogenesis. Biochemistry $\mathbf{5 2}$ 7242-7253. (https://doi.org/10.1021/bi401125v)

Rupprecht R, Papadopoulos V, Rammes G, Baghai TC, Fan J, Akula N, Groyer G, Adams D \& Schumacher M 2010 Translocator protein (18 $\mathrm{kDa}$ (TSPO) as a therapeutic target for neurological and psychiatric disorders. Nature Reviews: Drug Discovery 9 971-988. (https://doi. org/10.1038/nrd3295)

Sarel I \& Widmaier EP 1995 Stimulation of steroidogenesis in cultured rat adrenocortical cells by unsaturated fatty acids. American Journal of Physiology 268 R1484-R1490. (https://doi.org/10.1152/ ajpregu.1995.268.6.R1484)

Selvaraj V \& Stocco DM 2015 The changing landscape in translocator protein (TSPO) function. Trends in Endocrinology and Metabolism 26 341-348. (https://doi.org/10.1016/j.tem.2015.02.007)

Selvaraj V \& Stocco DM 2018 Letter to the editor: dubious conclusions on TSPO function. Endocrinology 159 2528-2529. (https://doi. org/10.1210/en.2018-00052)

Selvaraj V \& Tu LN 2016 Current status and future perspectives: TSPO in steroid neuroendocrinology. Journal of Endocrinology 231 R1-R30. (https://doi.org/10.1530/JOE-16-0241)

Selvaraj V, Stocco DM \& Tu LN 2015 Minireview: translocator protein (TSPO) and steroidogenesis: a reappraisal. Molecular Endocrinology 29 490-501. (https://doi.org/10.1210/me.2015-1033)

Selvaraj V, Tu LN \& Stocco DM 2016 Crucial role reported for TSPO in viability and steroidogenesis is a misconception. Commentary: conditional steroidogenic cell-targeted deletion of TSPO unveils a crucial role in viability and hormone-dependent steroid formation. Frontiers in Endocrinology 7 91. (https://doi.org/10.3389/ fendo.2016.00091)

Šileikyte J, Blachly-Dyson E, Sewell R, Carpi A, Menabò R, Di Lisa F, Ricchelli F, Bernardi P \& Forte M 2014 Regulation of the mitochondrial permeability transition pore by the outer membrane does not involve the peripheral benzodiazepine receptor (translocator protein of $18 \mathrm{kDa}$ (TSPO)). Journal of Biological Chemistry 289 13769-13781. (https://doi.org/10.1074/jbc.M114.549634)

Singh A, Dashnyam M, Chim B, Escobar TM, Dulcey AE, Hu X, Wilson KM, Koganti PP, Spinner CA, Xu X, et al. 2020 Anxiolytic drug FGIN-1-27 ameliorates autoimmunity by metabolic reprogramming of pathogenic Th17 cells. Scientific Reports 10 3766. (https://doi. org/10.1038/s41598-020-60610-5)

Spady DK \& Dietschy JM 1985 Rates of cholesterol synthesis and lowdensity lipoprotein uptake in the adrenal glands of the rat, hamster and rabbit in vivo. Biochimica et Biophysica Acta 836 167-175. (https://doi.org/10.1016/0005-2760(85)90063-3) https://joe.bioscientifica.com https://doi.org/10.1530/JOE-20-0189 (c) 2020 Society for Endocrinology Published by Bioscientifica Ltd. Printed in Great Britain 
Stocco DM \& Clark BJ 1996 Regulation of the acute production of steroids in steroidogenic cells. Endocrine Reviews 17 221-244. (https:// doi.org/10.1210/edrv-17-3-221)

Stocco DM, Zhao AH, Tu LN, Morohaku K \& Selvaraj V 2017 A brief history of the search for the protein(s) involved in the acute regulation of steroidogenesis. Molecular and Cellular Endocrinology 441 7-16. (https://doi.org/10.1016/j.mce.2016.07.036)

Tu LN, Morohaku K, Manna PR, Pelton SH, Butler WR, Stocco DM \& Selvaraj V 2014 Peripheral benzodiazepine receptor/ translocator protein global knock-out mice are viable with no effects on steroid hormone biosynthesis. Journal of Biological Chemistry 289

27444-27454. (https://doi.org/10.1074/jbc.M114.578286)

Tu LN, Zhao AH, Stocco DM \& Selvaraj V 2015 PK11195 effect on steroidogenesis is not mediated through the translocator protein (TSPO). Endocrinology 156 1033-1039. (https://doi.org/10.1210/ en.2014-1707)

Tu LN, Zhao AH, Hussein M, Stocco DM \& Selvaraj V 2016 Translocator protein (TSPO) affects mitochondrial fatty acid oxidation in steroidogenic cells. Endocrinology 157 1110-1121. (https://doi. org/10.1210/en.2015-1795)

Tvrzická E, Řezanka T, Krijt J \& Janoušek V 1988 Identification of very-long-chain fatty acids in rat and mouse harderian gland lipids by capillary gas chromatography-mass spectrometry. Journal of Chromatography 431 231-238. (https://doi.org/10.1016/ S0378-4347(00)83092-3)
Vahouny GV, Chanderbhan R, Hinds R, Hodges VA \& Treadwell CR 1978 ACTH-induced hydrolysis of cholesteryl esters in rat adrenal cells. Journal of Lipid Research 19 570-577.

Verma A, Nye JS \& Snyder SH 1987 Porphyrins are endogenous ligands for the mitochondrial (peripheral-type) benzodiazepine receptor. PNAS 84 2256-2260. (https://doi.org/10.1073/pnas.84.8.2256)

Wang HJ, Fan J \& Papadopoulos V 2012 Translocator protein (Tspo) gene promoter-driven green fluorescent protein synthesis in transgenic mice: an in vivo model to study Tspo transcription. Cell and Tissue Research 350 261-275. (https://doi.org/10.1007/s00441-012-1478-5)

Wang H, Zhai K, Xue Y, Yang J, Yang Q, Fu Y, Hu Y, Liu F, Wang W, Cui L, et al. 2016 Global deletion of TSPO does not affect the viability and gene expression profile. PLOS ONE 11 e0167307. (https://doi. org/10.1371/journal.pone.0167307)

Woodhouse MA \& Rhodin JAG 1963 The ultrastructure of the harderian gland of the mouse with particular reference to the formation of its secretory product. Journal of Ultrastructure Research 49 76-98. (https:// doi.org/10.1016/S0022-5320(63)80037-4)

Zhao AH, Tu LN, Mukai C, Sirivelu MP, Pillai VV, Morohaku K, Cohen R \& Selvaraj V 2016 Mitochondrial translocator protein (TSPO) function is not essential for heme biosynthesis. Journal of Biological Chemistry 291 1591-1603. (https://doi.org/10.1074/jbc.M115.686360)

Zoller LC \& Malamed S 1975 Acute effects of ACTH on dissociated adrenocortical cells: quantitative changes in mitochondria and lipid droplets. Anatomical Record 182 473-478. (https://doi.org/10.1002/ ar.1091820406)

Received in final form 18 June 2020

Accepted 13 July 2020

Accepted Manuscript published online 13 July 2020 (c) 2020 Society for Endocrinology Published by Bioscientifica Ltd. Printed in Great Britain 